\title{
RESENHA
}

\section{Comuna de Paris, Estado e Direito}

Carla Benítez Martins, Flávio Roberto Batista \& Gustavo Seferian (coords.), Comuna de Paris, Estado e Direito. Brasil: Editora RTM, 2021, 635 pp.

\section{Daniel J. García López ${ }^{1}$}

'Universidad de Granada, Granada, Espanha. E-mail: danieljgl@ugr.es. ORCID: https://orcid.org/0000-0003-0601-1395.

\section{Augusto Fernando Carrillo Salgado ${ }^{2}$}

${ }^{2}$ Universidad Nacional Autónoma de México (UNAM), Cidade do México, México. E-mail: fernando90@comunidad.unam.mx. ORCID: https://orcid.org/0000-0001-6107-4917.

\section{Julio César Muñoz Mendiola ${ }^{3}$}

${ }^{3}$ Universidad Nacional Autónoma de México (UNAM), Cidade do México, México. E-mail: julioderecho@comunidad.unam.mx. ORCID: https://orcid.org/0000-0002-8769-7984.

]

Resenha recebida em 3/05/2021 e aceita em 26/06/2021.

\section{$(\mathrm{cc}) \mathrm{EY}$}

This work is licensed under a Creative Commons Attribution 4.0 International License 


\section{Parte I. Os sentidos políticos da Comuna}

Uno de los ojos más críticos, y crípticos, de la Francia del siglo XIX fue, sin duda, Walter Benjamin. En el inventario en que consiste su Das Passagen-Werk podemos leer "la barricada resurge en la Comuna mejor y hasta más sólida que nunca" (Benjamin, 2013, p. 72). Si la barricada es situada como la imagen del mundo que viene, ¿̇encontramos también en aquella experiencia una suerte de barricada jurídica? El libro que reseñamos aquí quizás aporte cuestiones que nos lleven hacia una posible, y siempre abierta, respuesta.

El libro se abre con una primera parte dedicada a los sentidos políticos de la Comuna. Los textos los podríamos clasificar en los siguientes jalones: derecho (Ana Lia Almeida; Irene Sarrión dos Santos Guimarães; Marcus Orione; Odara Gonzaga de Andrade; Ricardo Prestes Pazello; Vitor Bartoletti Sartori) y potencia (Andityas Soares de Moura Costa Matos y Rodrigo Wagner Santos Ribeiro Filho; Bartriz Calló, Daniela Embón, Fernanda Azevedo y Fernando Kinas; Gustavo Seferian; Michael Löwy; Pablo Biondi; Pedro Luiz de Oliveira Pinto; Regina Stela Correa Vieira y Ana Claudia Rockemback; Tainã Góis). Estos jalones pueden ser leídos también como lo que la Comuna significó para lo ya dado (derecho, Estado) y lo que la Comuna significó para imaginar un futuro (potencia). Pasemos a plantear lo que nos aportan los y las autoras en ambos temas.

Con respecto a lo dado, Os decretos da Comuna: reflexões sobre direito $e$ revolução (Almeida, 2021, pp. 19-32) nos sitúa ante la experiencia jurídica de la comuna para entablar un diálogo sobre el carácter histórico del derecho y sus especificidades en momentos de transición revolucionaria con especial énfasis en las posibilidades de emancipación que este pudiera proyectar. Siguiendo con esta línea, A Comuna de Paris: uma fissura na subjetividade jurídica burguesa (Sarrión, 2021, pp. 99-113) nos plantea la experiencia de la Comuna como una fisura en la subjetividad jurídica burguesa. La modernidad trajo consigo la vinculación entre propiedad privada y derecho, de ahí que la subjetividad jurídica se construyera en torno a ese nexo con la propiedad privada. ¿Pudo la Comuna friccionar esta forma jurídica? La clase como realmente existente, más allá de la subjetividad jurídica, abrió el camino para construir un imaginario jurídico más allá del derecho moderno.

Pero no solo puso en tela de juicio la subjetividad jurídica. Como se traza en Comuna de Paris e Guerra: elementos para uma crítica ao Estado (Gonzaga, pp. 145-159), 
la Comuna también planteó una crítica radical a la forma-Estado -necesaria para construir una teoría de la historia de la clase trabajadora, como se expone en Às margens do Sena: por uma teoría da história da classe trabalhadora (Orione, 2021, pp. 115-134), que acompañó a la subjetividad jurídica y a la propiedad privada como elemento estructurador del sistema de producción capitalista. En este mismo sentido, como se explica en Formas rígidas e flexíveis em movimiento de ascensão e queda: direito e Estado sob a leitura de Marx a propósito da Comuna de Prais (Prestes, 2021, pp. 201-224), apuntaba ya el diagnóstico de Marx sobre la Comuna, así como el de Engels, tal como se desarrolla en Engels e a Comuna de Paris: sublevação, luta legal e revolução (Bartoletti, 2021, pp. 245-268). Aunque mantengamos una mirada crítica sobre la Comuna, siendo conscientes de sus debilidades, lo cierto es que su experiencia nos da posibilidad para pensar en otra forma de organización jurídico-política.

Es por ello por lo que, en esta primera parte del monográfico, podemos clasificar otros capítulos como potencias, como otras formas para imaginar un futuro, otro futuro a partir de la tradición de los oprimidos, como nos recuerda el autor de $A$ Comuna de Paris 1871: o salto de tigre em direção ao pasado (Löwy, 2021, pp. 135-142). Los autores de Uma anarqueologia da Comuna de Paris: sobre a potência das prácticas revolucionárias (Soares \& Santos, 2021, pp. 35-62) nos adentran en una anarqueología para pensar las formas-de-vida presentes (en el sentido que le da a este término Giorgio Agamben) a partir de la forma-de-vida acontecida en la Comuna. En esta, alejada del sujeto jurídico burgués, la dimensión cultural (especialmente artística) tendrá un papel clave. Es lo que nos proponen las y los escritores de Arte e política na Comuna (Calló et al., 2021, pp. 6381). Y esta forma-de-vida no puede quedar aislada, como el sujeto abstracto burgués, sino que está en relación con otras formas-de-vida, incluido el ecosistema. Por eso el autor de Pode a jibóia ser ecosocialista?: pontos para a retomada da experiência da Comuna de Paris como indutora da contemorânea revolução social e ecológica (Seferian, 2021, pp. 83-98) se centra en el pensamiento ecológico que encuentra una experiencia en la lucha de la Comuna.

Por su parte, quien presenta el artículo A moral revolucionária dos communards: moralidade, violência e luta de classes (Biondi, 2021, pp. 162-170) se ocupa del problema moral del uso de la violencia en las luchas sociales. De ella también se ocupa el autor de Coluna Vendôme ao chao: uma comuna necesariamente internacionalista e antirracista (de Oliveria, 2021, pp. 171-188) para plantear la lucha internacionalista y antirracista de 
la Comuna. En esa lucha tuvieron protagonismo varias figuras, de las que podemos destacar Louise Michel y su contribución a la educación emancipadora, como apuntan en su trabajo las autores de Louise Michel: memórias, luta e cuidado na Comuna de Paris (Correa \& Rockemback, 2021, pp. 189-200). Siguiendo con la lucha protagonizada por mujeres en la Comuna, Tainã Góis (Góis, 2021, pp. 225-243) nos adentra en los planteamientos feministas que se desarrollaron durante la experiencia comunal.

\section{Parte II. Enfrentamentos jurídico-políticos dos comunardos e comunardas}

Ninguna persona podría negar que el capitalismo, en tanto sistema económico de producción y mecanismo de control ideológico, está plagado de contradicciones. Gracias al capitalismo se han logrado avances espectaculares en todos los dominios del saber humano. Parafraseando el Manifiesto del Partido Comunista, gracias al capitalismo se "han creado obras maravillosas, muy distintas a las pirámides egipcias, a los acueductos romanos y a las catedrales góticas". Sin embargo, el capitalismo ha propiciado, paradójicamente, la explotación irracional de los recursos naturales, la consecuente destrucción del medio ambiente, enajenación de los seres humanos y desmantelamiento de los sistemas de seguridad social.

Naturalmente, en unas cuantas líneas sería imposible dar cuenta cabal del fenómeno descrito. Además, ese tampoco es el propósito de este texto. Por ahora, restaría mencionar que, tanto la crisis económica de 2008, como la pandemia global ocasionada por la aparición del virus SARS-CoV-2, han subrayado dichas contradicciones. ¿Dónde encontrar soluciones a esta época de crisis? Sin duda alguna, la Comuna de París es una pieza clave en esta búsqueda constante de respuestas o soluciones. La Comuna fue una experiencia corta, pero intensa, que ha servido de brújula a todo el género humano desde su origen. Tratase, por decirlo de alguna manera, de un experimento social parisino acaecido del 18 de marzo al 28 de mayo de 1871.

La Comuna fue, sin duda alguna, uno de los primeros intentos por horizontalizar las relaciones de producción y terminar con la explotación del ser humano. Dicha horizontalización entrañaba, por supuesto, un gran número de medidas para lograr su instauración. Si bien es cierto esta meta no pudo alcanzarse debido a la brutal represión 
de las fuerzas conservadoras de la Francia decimonónica, la experiencia de la Comuna no deja de encontrar resonancia en el momento presente.

Es por ello por lo que, a ciento cincuenta años de distancia encuentro mucho sentido escribir un texto colectivo que no solo da cuenta de las repercusiones que la Comuna tuvo para Francia y Europa, sino para el resto del mundo occidental. Lo que es más, una característica innovadora del texto que se reseña es, precisamente, la búsqueda por adecuar las consecuencias de la Comuna a la realidad contemporánea de Brasil y, por qué no, al resto de Iberoamérica. Para algunas personas este intento podría parecer descabellado, para otras una decisión sabia. Empero, me decanto por esta última posición porque la luchas, los ideales de los comuneros serían sepultados por el peso de la historia sin esta clase de textos. Más aún, en un mundo dominado por la inmediatez de los medios de transporte y redes sociales (comunicación en tiempo real) ciento cuenta años podría parecer mucho tiempo. Sin embargo, ello no es así pues tan solo ha transcurrido un suspiro en la historia universal del ser humano. En otras palabras, la Comuna es un hecho histórico-social que parece haber ocurrido el día de ayer.

Los quince artículos que integran la sección II, intitulada Enfrentamentos jurídicopolíticos dos comunardos e comunardas, del libro Comuna de Paris, Estado e Direito, retratan de manera magistral, la ardua lucha política de las comuneras y comuneros por lograr una sociedad más justa. Pero no solo eso, dichos artículos permiten reexaminar los retos del mundo contemporáneo en relación con la experiencia comunal.

En el texto Sobre o problema da religião: a Comuna e para além dela (Passos, Lopes \& Fernandes, 2021, pp. 272-288), los autores tratan de responder la siguiente pregunta de investigación: ¿Cuál era el papel de la religión en la Comuna de París? La pregunta conduce, indefectiblemente, a afrontar dos bemoles. Primero, emplear métodos y técnicas propias de la sociología. Segundo, la ausencia de registros estadísticos debido a la efímera existencia de la Comuna. A pesar de estos escollos, los autores concluyen con éxito la empresa. En efecto, para desentrañar este misterio, emplean un marco teórico-conceptual claramente marxista. Es importante destacar que, no adoptan un criterio estrictamente temporal. Esto es, no se limitan a examinar los textos más próximos al periodo de la Comuna. Por el contrario, tratan de descubrir la manera en que la experiencia de la Comuna estuvo presente en la obra del filósofo de Tréveris a lo largo del tiempo. El método y marco teórico empleados les permite concluir: 1) la breve existencia de la Comuna de París es un obstáculo para el examen detallado del papel de 
la religión entre los comuneros y 2) la religión no fue cuestionada en sus postulados deontológicos; tan solo su función material estuvo sujeta a examen por los comuneros.

El artículo Caminhos à construção de uma nova sociedade: a Comuna de Paris sob a perspectiva da tributação (Expedito, 2021, pp. 289-302), comienza con una descripción del contexto histórico. Posteriormente, la autora examina el papel del derecho tributario antes y durante la experiencia comunal. Cabe destacar que, el sistema tributario precomunal era regresivo e indirecto: la fuente principal de ingresos eran los gravámenes de bienes y servicios. La gente no pagaba impuestos debido a sus ingresos, sino por su consumo. Naturalmente, los empresarios arrojaban la carga fiscal al adquiriente final. En otras palabras, el sistema fiscal francés era una especie de gran tienda de raya. Para terminar con esta injusticia los comuneros, por su parte, propusieron un sistema fiscal progresivo y directo que puede resumirse de la siguiente forma: que pague más, quien tenga más.

En A saúde nas lutas da clase trabalhadora pela superação da orden do capital: apontamentos a partir dos processos revolucionários e das experiências combativas operárias (Bechara, 2021, pp. 303-318), su autor trata de exponer el impacto que tuvo la experiencia de la Comuna de París en Rusia, China, Italia y Brasil a lo largo de diferentes épocas. Esto es, durante la conformación de la extinta URSS, revolución cultural de Mao, reconstrucción postfascista y movimiento metalúrgico de Sao Paulo. Aunque el artículo parece promisorio, en realidad adolece de dos grandes bemoles. Primero, los periodos temporales y países que analiza son aleatorios, ¿por qué motivo los eligió? Segundo, el objetivo principal de su documento se diluye paulatinamente a lo largo del artículo. El lector recorre línea tras línea esperando encontrar una explicación contundente sobre el derecho a la salud en la Comuna de Paris y su impacto posterior en otros países, pero dicha explicación jamás llega.

Los efectos de una revolución permean todos los ámbitos culturales del ser humano. El derecho no es una excepción, tal y como queda demostrado en Incendiários, incendiárias! Múltiplos sentidos de crime, criminalidade e criminalização diante do acontecimento histórico da Comuna de Paris (Benitez, 2021, pp. 319-344). La experiencia de la Comuna de París prueba que el derecho moderno, aunque en apariencia neutro, no deja de ser, en una de sus dimensiones, más que una expresión de los valores burgueses. Este fenómeno se hace patente, sobre todo, en el derecho penal. Por una parte, su núcleo es la protección de la propiedad privada. Por la otra, permite la imposición de penas a un 
sector considerable de la población cuyo delito principal es carecer de un empleo o medios de producción. Así, la autora destaca el impacto de la Comuna en la obra de Georg Rusche, Pachukanis, Stutchka e, inclusive, Roberto Lyra Filho.

Luta por moradia: da Comuna de Paris ao Brasil no século XXI (Cirqueira et al., 2021, pp. 345-371) es un texto de altos vuelos. En efecto, se trata de un artículo novedoso y de gran calidad, elaborado por cinco jóvenes académicos de Brasil. La Comuna de París y el mundo contemporáneo comparten un problema: la vivienda para los trabajadores. Uno de los principales problemas de los centros urbanos parisinos durante la Comuna era el número reducido de habitaciones para los operarios; este fenómeno produjo la especulación inmobiliaria en perjuicio de los trabajadores. A pesar de los "avances" democráticos del mundo moderno, el problema subsiste. Mediante un estudio de caso, los autores evidencian que, en los grandes centros de trabajo de Brasil, poco más de la mitad de los trabajadores viven en hogares autoconstruidos. Esto es, en chozas erguidas sin planificar; construidas a partir de materiales de ínfima calidad. La Comuna ofrece, desde luego, interesantes respuestas. Primero, mediante diferentes decretos se trató de remodelar los centros urbanos. Verbigracia, tornase gratuito la utilización de los transportes públicos, se prohibió el uso de autos particulares y se dispusieron un millar de bicicletas de libre utilización. Segundo, también se prohibió la amortización de moradas y se ordenó la elaboración de inventarios como requisito para arrendar un inmueble.

Aunque Notas sobre o serviço público: as disputas capital-trabalho pela apropriação do erário do Estado burguês (da Silva \& Henrique, 2021, pp. 372-398) y Administração das coisas entrevista pela crítica prática ao Estado político-burocrático (Paço, 2021, pp. 399-412) son dos textos que se encuentran intimamente vinculados; también son dos propuestas en clara oposición. El primero de ellos representa una perspectiva más moderada, el segundo una postura más crítica o radical. En Notas sobre o serviço público se subraya que el Estado ha sido, desde la Comuna, el objeto de deseo de la burguesía. Por una parte, ha tratado de reducírsele para apropiarse de funciones como la educación y salud. Es decir, ofrecer los servicios que el Estado debe garantizar a cambio de una remuneración. Por la otra, la burguesía desea mantener un andamiaje mínimo para poder oprimir a la clase trabajadora. La Comuna de París permitió repensar la idea del Estado. En primer término, fue colocado como un instrumento para tratar de disminuir la igualdad. Esto es, crear un Estado al servicio de la gente. En segundo lugar, 
los comuneros establecieron un régimen estricto salarial. En efecto, las remuneraciones entre los funcionarios públicos y obreros deberían ser los mismos. Por último, este documento no solo es una narración histórica de la idea del Estado en la Comuna de París; por el contrario, también analiza la estructura burocrática de Brasil para determinar si la burguesía se ha apropiado de las responsabilidades estatales o, por el contrario, las funciones de garantía del Estado han aumentado. En Administração das coisas entrevista pela crítica prática ao Estado político-burocrático (Paço, 2021, pp. 399-412), por su parte, el autor muestra una perspectiva más radical. De acuerdo con él, en realidad los comuneros deseaban destruir por completo el aparato estatal burgués para edificar una nueva organización.

Militarização, segurança pública e defesa territorial: lições desde a Comuna de Paris (Martins, 2021, 413-432) es un artículo donde se explica el intento por desmilitarizar a la sociedad por parte de los comuneros. A pesar de la efímera existencia de la Comuna, los habitantes parisinos dictaron medidas en donde las funciones de guardia eran asumidas por la propia ciudadanía y, además, prohibieron la entrada de las fuerzas castrenses en la Comuna. El autor no se limita a explicar el contenido de la regulación dictada al respecto; por el contrario, destaca la importancia del tema en relación con la propia realidad brasileña. En efecto, con el propósito de poner un punto final a la lucha fratricida al interior de Brasil, sostiene el autor que es menester terminar con el proceso de militarización de aquél país.

El objetivo de Direito do trabalho e transição: elementos para pensar o direito do trabalho contemporâneo à luz da Comuna de Paris (Lenzi \& Batista, 2021, pp. 433-446) es dar respuesta a la siguientes preguntas: ¿Qué fisonomía, de acuerdo con los comuneros, debía adquirir el Derecho del trabajo? ¿En qué forma se relaciona la experiencia de la Comuna con la realidad laboral brasileña actual? En otras palabras, los autores de este documento debaten las medidas adoptadas por los comuneros en el ámbito del derecho del trabajo; entendiendo como tal un régimen de transición para alcanzar la igualdad material entre los seres humanos, con el propósito de rescatar aquellos elementos que puedan permitir hacer frente a los retos del derecho del trabajo contemporáneo.

Por lo que respecta a A antessala da Comuna de Paris: a educação como eixo articulador de um projeto societal da classe trabalhadora (Barros, 2021, pp. 447-474), su autora destaca el papel que la educación interpretó al interior de la Comuna como una de las herramientas más importantes para la transformación de la sociedad en la 
organización de las clases sociales. Comienza realizando una descripción de la función y forma en que se impartía la educación en Francia justo antes de la experiencia de la Comuna. Por una parte, la educación era un elemento de segregación social. Por la otra, quienes tenían acceso a una formación escolar eran instruidos en la obediencia a la burguesía y sus valores. La Comuna propuso una escuela laica y gratuita cuyo objetivo principal era acabar con la desigualdad entre los seres humanos.

"Respeitosamente diante das portas do Banque de France": a questão transicional do controle financeiro pelos trabalhadores e trabalhadoras (Vasconcelos, 2021, pp. 475492) podría ser considerado, hasta cierto punto, como una suerte de texto complementário de Caminhos à construção de uma nova sociedade: a Comuna de Paris sob a perspectiva da tributação. Sin embargo, la diferencia radica en que, efectivamente, en este artículo el autor explica ampliamente la organización económica de los comuneros. En otras palabras, no solo se centra en el sistema de recaudación fiscal, sino que expone el modelo económico de la Comuna en su conjunto.

En Eleição de juízes e democratização do judiciário (Souto \& Valdete, 2021, pp. 493-498) sus autores destacan dos características del sistema de impartición de Justicia comunero: 1) sus mecanismos de elección democráticos y 2) la reducción de los salarios de los juzgadores. A diferencia de lo que enarbolan los sistemas burgueses de impartición de Justicia, inclusive los contemporáneos, todo juzgador debería ser electo democráticamente y no percibir salarios exorbitantes. Por una parte, la mayoría de los sistemas burgueses tienen vedada la elección democrática de los jueces so pretexto de "politizar" su función. Por la otra, perciben salarios estratosféricos por su servicio para que "no se corrompan". De la Comuna se puede aprender que: 1) la función judicial es esencialmente política y 2) no existe cantidad alguna que haga incorruptibles a los juzgadores.

De acuerdo con lo que se expone en Extinção da pena de morte e a morte dos comunardos e das comunardas (Rodrigues, 2021, pp. 499-511), la pena de muerte no cumple propiamente una función disuasiva del crimen; por el contrario, es uno de los instrumentos más efectivos de la burguesía para acabar con sus enemigos. Por tanto, la abolición de la pena de muerte por parte de los comuneros fue, en realidad, una de las expresiones más sublimes de empatía y humanidad. En efecto, un ser humano puede devenir criminal debido a la presión del sistema capitalista; puede, por ejemplo, verse obligado a terminar con la vida de otra persona por hambre. En ese sentido, ¿’por qué 
imponerle una medida tan dura, cuando él mismo es víctima de un sistema de producción que lo conduce hacia el crimen? ¿Qué decir de los llamados "enemigos políticos"? ¿Son realmente enemigos del Estado o un riesgo para el statu quo de la burguesía? En este artículo, hacia la parte final, se expone el lado más oscuro de la pena de muerte pues miles de personas fueron masacradas para terminar con la experiencia comunal al ser considerados criminales o enemigos del Estado cuando, en realidad, eran patriotas que luchaban por mejorar sus condiciones de vida.

Domar a besta: uma reflexão sobre propriedade privada, função social e o direito na sociedade capitalista (De Melo, 2021, pp. 512-530) constituye una reflexión sobre la propiedad privada en el sistema de producción capitalista. Este documento retrata perfectamente la diferencia entre lo que se dice en un papel y lo que acontece en la realidad. En efecto, en toda constitución moderna, es decir, en aquellos ordenamientos supremos emanados de la revolución industrial burguesa, el derecho a la propiedad privada se encuentra reconocido y garantizado para todos los seres humanos. Empero, el sistema de producción capitalista está diseñado para impedir la materialización de este derecho para la gran mayoría de seres humanos. En otras palabras, la constitución establece el derecho a la propiedad privada pero el resto de las normas secundarias son creadas en sentido contrario porque imponen gravámenes y directrices tan estrictas que resulta imposible consolidar un patrimonio. Por desgracia, este fenómeno no es un mero relato histórico; por el contrario, es una terrible realidad para la mayoría de las sociedades contemporáneas. Sin duda alguna, la experiencia comunal tiene mucho que ofrecer a las generaciones actuales, sea desde un punto de vista meramente utópico, sea como un sistema objetivo de normas cuya finalidad es reducir la desigualdad entre los seres humanos.

Moral, trabalho e prostituição na Comuna (Molitor, 2021, pp. 531-552) es un documento intenso, interesante y profundo pues constituye una reflexión desencarnada del papel de la mujer en la Comuna y, en general, en todo el sistema que ésta inspiró (verbigracia, extinta URSS). Con frecuencia la experiencia de la Comuna es idealizada o romantizada pues se observa como un avance para alcanzar la igualdad entre todos los "hombres", sin embargo, esta idealización no deja de ser elaborada desde el punto de vista masculino. En realidad, sea desde el sistema capitalista de producción, sea desde el comunista, la mujer ha sido colocada en un papel de inferioridad lo que se traduce en una percepción salarial inferior que, consecuentemente, la posiciona en una situación de 
marginación y vulnerabilidad. En ese sentido, son muy sabias las palabras de Thamíris Evaristo Molitor al destacar la importancia de: "mirar experiencias pasadas para hacer una lectura más adecuada del presente y producir una teoría comprometida con la transformación de la sociedad".

Parte III. Comuna de Paris e as lutas revolucionárias de ontem e hoje

Sin lugar a duda la Comuna de París de 1871 representó un punto de inflexión para los pensamientos filosóficos político, moral y jurídico y, en general, para la historia de la humanidad, pues como proposición revolucionaria (si se prefiere resistencia popular), sus efectos y alcances no podrían determinarse con precisión desde un solo horizonte epistémico. En tal sentido, la obra que se comenta, en general, se encarga de algunas de las implicaciones de la Comuna en la actualidad, sobre todo, de cómo algunos de los cuestionamientos de aquella época no solo persisten, sino que se han diversificado y transformado en fenómenos aún más complejos. Lo que podría ser un acierto de la obra o, por el contrario, una suerte de diversas y divergentes posturas que confluyen, en abstracto, en la Comuna. A mi parecer, la obra colectiva si logra una convergencia de varias propuestas que no solo describen el significado de la Comuna, sino que también presentan críticas actuales que desvelan una cierta vigencia del significado de la Comuna.

Precisamente, la tercera parte de la obra da cuenta de lo mencionado con su título: Comuna de Paris e as lutas revolucionárias de ontem e hoje. Y es que los últimos seis trabajos del libro ofrecen una difícil labor de conciliar retrospectiva-prospectiva en un tiempo presente, esto es, la comprensión de algunas de las problemáticas actuales mediante su análisis histórico y crítico, así como la propuesta de una suerte de utopías. En esto último, es donde se podría reprochar a los autores un fuerte idealismo para brindar soluciones pragmáticas a la realidad contemporánea; sin embargo, me parece que el objetivo de algunos trabajos no es normativo (propositivo), sino más bien descriptivocomparativo de las problemáticas de aquel tiempo y su permanencia.

En el ensayo intitulado Utopias desinstituintes: potências da Comuna em Rojava (Abrantes \& de Sá, 2021, pp. 555-574), las autoras dan cuenta de una refundación social a partir de las ideas de Andytias Matos, pues conectan las luchas del pasado y las experiencias críticas utópicas, para proponer la construcción de presentes (o futuros) 
diferentes. De esta forma, primero realizan un análisis de la Comuna de París, a partir del materialismo histórico marxista. Posteriormente, las autoras se adentran a una crítica por demás interesante, pues no solo dan cuenta de un Estado capitalista, sino de una estructura patriarcal del mismo. Además de hacer un paralelismo entre la Comuna de París y el movimiento revolucionario de Rojava durante la guerra civil siria en 2012, para señalar algunas de las implicaciones políticas y sus consecuencias en una reformulación de la concepción del Estado-nación, concebido también como símbolo del patriarcado.

Las autoras concluyen proponiendo que las experiencias utópicas de la Comuna de París y Rojava demuestran las contradicciones performativas del sistema capitalista, y señalando como la experiencia comunal de ambos acontecimientos: podrían rehacer la propia realidad para experimentar lo imposible a manera de utopía. Sin embargo, un cuestionamiento importante que podría hacerse al trabajo es: ¿si solo en el Estado capitalista existen esas estructuras patriarcales? Para el caso, lo que las autoras centran como una utopía tanto en la Comuna y Rojava, es precisamente a una refundación de la sociedad a través de las prácticas comunitarias, en donde se supone la estructura patriarcal no existiría más (de allí lo utópico).

En el segundo ensayo, al que el autor titula Entre Comunas e Quilombos: Canudos e asbarricadas del sertão (De Castro, 2021, pp. 575-586), no solo se desvelan aspectos históricos y contextos políticos y económicos de lo sucedido antes y durante la Comuna de París, pues también se da cuenta del pensamiento revolucionario que se gestaba en el pueblo brasileño. Lo interesante es como el autor analiza el papel que pudo jugar la religión y la cuestión racial para la imposición de un régimen capitalista. Cuestión que invita al lector a preguntarse si la religión y las cuestiones raciales siguen siendo centrales en muchas de las problemáticas de nuestros días, ya que si bien el autor no concluye de forma clara en torno a esa vigencia, sí señala una causa-herencia que ha impactado a las regiones más pobres de Brasil (sertão); para el caso, una forma de capitalismo o de explotación de las personas por las personas.

En ese sentido, el autor ve como una solución al carácter revolucionario, mismo que inspiró a la Comuna de París, para refundar una forma de vida pre-capitalista de dicha explotación. Lo que desvelaría el carácter utópico de lo propuesto que, sin embargo, es valioso por su trasfondo reaccionario y divergente de un hecho que no puede considerarse como una utopía, es decir, la desigualdad social. Para el caso, la crítica hacia las estructuras capitalistas de ayer y hoy que producen desigualdades estructurales, y que 
se agudizan en contextos de exclusión racial, están presentes en la descripción histórica que el autor hace de los quilombos.

El tercer trabajo titulado A Comuna e uma Revolução inacabada na Bolivia (Junior, 2021, pp. 587-598), toma como un punto cardinal el breve periodo que la Comuna de París funcionó en el poder de facto, para luego partir de un cuestionamiento central: ¿existe alguna diferencia entre elegir un representante popular o una mayoría en una asamblea representativa con la toma de poder por la fuerza durante la Comuna parisina? Cuestionamiento que el autor desarrolla mediante un paralelismo con la actual situación política y jurídica que se ha desarrollado en Bolivia; nuevamente presentándose ese análisis retrospectivo-prospectivo. Aunque habría que advertir que ese estudio comparativo no da cuenta, de manera total, con el impacto que tuvo la Comuna para los movimientos obreros de América Latina, cuestión obvia si se toma en cuenta el tamaño del trabajo; no obstante, induce a otras líneas de investigación en torno a otras regiones latinoamericanas.

Precisamente, el autor hace una retrospectiva en torno a cómo la Comuna no solo representó una ruptura para una refundación del Estado, sino que su legado y experiencia permeó, de alguna manera, hasta Latinoamérica y hasta nuestros días, concretamente, en la construcción de un Estado plurinacional en Bolivia. Ya que dicha construcción ha representado una forma de decolonización que, en el trasfondo, si bien no se inspiró en la Comuna, sí se pueden desvelar importantes lecciones de esta última. Al final, como el autor refiere, la Comuna de París permanecerá durante muchos años como una experiencia fundamental para las personas que no estén de acuerdo con el curso del mundo en la estela del capitalismo. En todo caso, hubiese sido interesante profundizar en la convergencia de sentimientos patrióticos y nacionalistas que se han desarrollado en la región latinoamericana, pues esa sería una línea distintiva, por ejemplo, del Estado plurinacional boliviano.

El cuarto trabajo en su título presupone su tesis principal: A comuna de París no Brasil (Badaró, 2021, pp. 599-612). Para el caso, como el propio autor refiere, el trabajo da cuenta de las repercusiones de la Comuna de París en Brasil. Al principio se analizan las repercusiones que tuvo la Comuna en el movimiento obrero internacional, es decir, centra las bases teóricas e ideológicas marxistas que inspiraron y, en algún sentido, proporcionaron las ideas revolucionarias en Brasil. Posteriormente, la revisión de ese impacto se centra en la lucha de clases que se libró en aquel tiempo, pues, al igual que 
sucedió en la Comuna parisina, se buscó, de manera general, una emancipación de las trabajadoras y los trabajadores esclavizados, pero, mediante un proceso gradual.

El autor concluye señalando que la coyuntura constante entre individuos proletarios y capitalistas (aún en la actualidad); se guiará por una base mutualista. Para el caso, la hipótesis del trabajo se centra en cómo se dio un constante flujo de ideas del movimiento obrero europeo después de la Comuna parisina hacia la clase trabajadora, artística e industrial en Brasil. Pues, desde la perspectiva del autor, aún en democracia a veces el socialismo influirá en una lucha constante entre individuos proletarios y capitalistas; lo que no queda claro es si dicha influencia se dio con la misma inercia que en la Comuna o se particularizó en el país sudamericano.

El penúltimo trabajo, A comuna de Paris na Revoluçaõ cultural chinesa (Bilharinho, 2021, pp. 613-622), nuevamente da cuenta del objetivo de esta última parte del libro: señalar las implicaciones de la Comuna de París en otras latitudes. Para el caso, el autor se centra en un razonamiento analítico y comparativo del significado de comuna para la Revolución Cultural china, es decir, la elección de los dirigentes y la sustitución del aparato estatal (sobre todo las supresión de las fuerzas armadas), por y a cargo de las masas trabajadoras, así como la diferencia sustancial entre la concepción del Estado burgués (capitalista) y la Comuna parisina, esto es, la unificación del poder ejecutivo y legislativo en un órgano elegido y constituido por las masas trabajadoras; lo cual no se presenta en la Revolución Cultural china de forma clara.

El autor señala que, si bien se puede hablar de una influencia de la Comuna parisina en la Comuna de Shanghái, al final la transición de China al comunismo se apartaría de un fundamento en la lucha de clases, ya que la Revolución Cultural en sí misma no se caracterizó por una clase social específica, ni tampoco se distinguió por la posición en sociedad de las personas, sino más bien por una suma de personas con ideas y comportamientos (cultura) similares. Precisamente, el autor intenta desvelar en su trabajo diferencias entre la Comuna parisina y la Revolución china, lo cual logra plasmar de forma clara, al señalar varias de las variables que pudieron influir en la asimilación de la Comuna en la Revolución: como el fuerte arraigo cultural oriental.

En el último de los trabajos, Comuna e Revolução na América Central: Fetichismo e poder e a reabilitação do político, converando com K. Marx e E. Dussel sobre a constituição "de um governo do povo pelo povo" (Massahud, 2021, pp. 623-634), el autor se propone analizar, desde las ideas de la Comuna parisina, la actual tensión entre 
democracia y capitalismo. Para ello contrapone, por un lado, la idea de Karl Marx de que el gobierno proletariado se basa en un gobierno del pueblo para el pueblo y, por otro lado, la idea dusseliana de que la política puede representar un medio de transformación real de la sociedad. Primero, el autor desarrolla las ideas marxistas de la democracia en la Comuna de París, sobre todo, hace un énfasis en que la sustitución de un gobierno de la clase obrera en el fondo significó un gobierno del pueblo para el pueblo, aunque también daría cuenta de las limitantes que la Francia de aquel tiempo tendría respecto de algunas ideas provenientes del liberalismo burgués. Precisamente, lo último serviría de punto de partida para desarrollar algunas críticas de Dussel a la izquierda marxista latinoamericana, como su cierto grado de eurocentrismo y positivismo; sin embargo, también reconocería una fuerte convicción en la idea de revolución como único y real cambio político.

El trabajo intenta hacer una especie de convergencia práctica entre las ideas de la Comuna parisina y el carácter revolucionario heredado de la misma en Latinoamérica, ello, representado en la Revolución cubana como proyecto de transformación radical de la sociedad. Asimismo, introduce, como herramienta teórica (así la llama él), una desmitificación de la política entendida solo como dominación desde la perspectiva dusseliana, pues concluye que esta última representa la manera de constituir otra forma de sociedad; la cual solo podría ser forjada por nosotros mismos como sociedad. En este punto, no se puede dejar de lado que la proposición, si la podemos llamar así, que considera esa desmitificación de la política, también podría significar una sustitución de tal dominación para implantar, posiblemente, otro tipo de dominación ahora en la forma de un poder socialista. Cuestión que hubiese sido interesante abordar en el trabajo. No obstante, este trabajo es uno de los que se muestra propositivo-descriptivo de la realidad latinoamericana, por tanto, de gran valía en la obra.

Para finalizar, si algo puede desvelarse de esta obra colectiva de gran tamaño, no solo por sus páginas, sino por su significado intrínseco, es que no solo da cuenta de una conmemoración intelectual de uno de los acontecimientos históricos más trascendentes de la humanidad, sino que la obra da cuenta también de una pluralidad de consecuencias e interpretaciones de lo que hace ciento cincuenta años representó la Comuna de París, porque nos enseña que la idea revolucionaria de aquella época sigue teniendo vigencia, pero también desvela una necesidad de trabajos con un eje crítico que pueda (re)posicionar la discusión pública en distintas realidades sociales, en torno a las formas o nuevas formas de explotación de las personas por las personas. 


\section{Fuentes de consulta}

Abrantes, A.C. \& De Sá, J.C. (2021). Utopias desinstituintes: potências da Comuna em Rojava. En C. B. Martins, F. R. Batista \& G. Seferian (Orgs.), Comuna de Paris, Estado e Direito, Belo Horizonte: RTM.

Almeida, A.L., (2021). Os decretos da Comuna: reflexões sobre direito e revolução. En C. B. Martins, F. R. Batista \& G. Seferian (Orgs.), Comuna de Paris, Estado e Direito, Belo Horizonte: RTM.

Badaró, M. (2021). A comuna de París no Brasil. En C. B. Martins, F. R. Batista \& G. Seferian (Orgs.), Comuna de Paris, Estado e Direito, Belo Horizonte: RTM.

Barros, J. (2021). A antessala da Comuna de Paris: a educação como eixo articulador de um projeto societal da classe trabalhadora. En C. B. Martins, F. R. Batista \& G. Seferian (Orgs.), Comuna de Paris, Estado e Direito, Belo Horizonte: RTM.

Bartoletti, V. (2021). Engels e a Comuna de Paris: sublevação, luta legal e revolução. En C. B. Martins, F. R. Batista \& G. Seferian (Orgs.), Comuna de Paris, Estado e Direito, Belo Horizonte: RTM.

Bechara, B. S., (2021). A saúde nas lutas da clase trabalhadora pela superação da orden do capital: apontamentos a partir dos processos revolucionários e das experiências combativas operárias. En C. B. Martins, F. R. Batista \& G. Seferian (Orgs.), Comuna de Paris, Estado e Direito, Belo Horizonte: RTM.

Benitez, C. (2021). Incendiários, incendiárias! Múltiplos sentidos de crime, criminalidade e criminalização diante do acontecimento histórico da Comuna de Paris. En C. B. Martins, F. R. Batista \& G. Seferian (Orgs.), Comuna de Paris, Estado e Direito, Belo Horizonte: RTM.

Benjamin, W. (2013). París, capital del siglo XIX, Madrid: Abada.

Biondi, P. (2021). A moral revolucionária dos communards: moralidade, violência e luta de classes. En C. B. Martins, F. R. Batista \& G. Seferian (Orgs.), Comuna de Paris, Estado e Direito, Belo Horizonte: RTM.

Bilharinho, M. (2021). A comuna de Paris na Revoluçaõ cultural chinesa. En C. B. Martins, F. R. Batista \& G. Seferian (Orgs.), Comuna de Paris, Estado e Direito, Belo Horizonte: RTM.

Calló, B. et al., (2021). Arte e política na Comuna. En C. B. Martins, F. R. Batista \& G. Seferian (Orgs.), Comuna de Paris, Estado e Direito, Belo Horizonte: RTM. 
Cirqueira et al., (2021). Luta por moradia: da Comuna de Paris ao Brasil no século XXI. En C. B. Martins, F. R. Batista \& G. Seferian (Orgs.), Comuna de Paris, Estado e Direito, Belo Horizonte: RTM.

Correa, R. S. \& Rockemback, A.C., (2021). Louise Michel: memórias, luta e cuidado na Comuna de Paris. En C. B. Martins, F. R. Batista \& G. Seferian (Orgs.), Comuna de Paris, Estado e Direito, Belo Horizonte: RTM.

Da Silva \& Henrique (2021). Notas sobre o serviço público: as disputas capital-trabalho pela apropriação do erário do Estado burguês. En C. B. Martins, F. R. Batista \& G. Seferian (Orgs.), Comuna de Paris, Estado e Direito, Belo Horizonte: RTM.

De Castro, V. (2021). Entre Comunas e Quilombos: Canudos e as barricadas del sertão. En C. B. Martins, F. R. Batista \& G. Seferian (Orgs.), Comuna de Paris, Estado e Direito, Belo Horizonte: RTM.

De Melo, T. (2021). Domar a besta: uma reflexão sobre propriedade privada, função social e o direito na sociedade capitalista. En C. B. Martins, F. R. Batista \& G. Seferian (Orgs.), Comuna de Paris, Estado e Direito, Belo Horizonte: RTM.

De Moura et al., (2021). Uma anarqueologia da Comuna de Paris: sobre a potência das prácticas revolucionárias. En C. B. Martins, F. R. Batista \& G. Seferian (Orgs.), Comuna de Paris, Estado e Direito, Belo Horizonte: RTM.

De Oliveira, P. (2021). Coluna Vendôme ao chao: uma comuna necesariamente internacionalista e antirracista. En C. B. Martins, F. R. Batista \& G. Seferian (Orgs.), Comuna de Paris, Estado e Direito, Belo Horizonte: RTM.

Dos Santos Guimarães, I. M., (2021). A Comuna de Paris: uma fissura na subjetividade jurídica burguesa. En C. B. Martins, F. R. Batista \& G. Seferian (Orgs.), Comuna de Paris, Estado e Direito, Belo Horizonte: RTM.

Expedito, B.M. (2021). Caminhos à construção de uma nova sociedade: a Comuna de Paris sob a perspectiva da tributação. En C. B. Martins, F. R. Batista \& G. Seferian (Orgs.), Comuna de Paris, Estado e Direito, Belo Horizonte: RTM.

Gonzaga, O. (2021).Comuna de Paris e Guerra: elementos para uma crítica ao Estado. En C. B. Martins, F. R. Batista \& G. Seferian (Orgs.), Comuna de Paris, Estado e Direito, Belo Horizonte: RTM.

Junior, G.L. (2021). A Comuna e uma Revolução inacabada na Bolivia. En C. B. Martins, F. R. Batista \& G. Seferian (Orgs.), Comuna de Paris, Estado e Direito, Belo Horizonte: RTM. 
Lenzi, J. \& Batista, F.R. (2021). Direito do trabalho e transição: elementos para pensar o direito do trabalho contemporâneo à luz da Comuna de Paris. En C. B. Martins, F. R. Batista \& G. Seferian (Orgs.), Comuna de Paris, Estado e Direito, Belo Horizonte: RTM.

Löwy, M. (2021). A Comuna de Paris 1871: o salto de tigre em direção ao passado. En C. B. Martins, F. R. Batista \& G. Seferian (Orgs.), Comuna de Paris, Estado e Direito, Belo Horizonte: RTM.

Martins, F.N. (2021). Militarização, segurança pública e defesa territorial: lições desde a Comuna de Paris. En C. B. Martins, F. R. Batista \& G. Seferian (Orgs.), Comuna de Paris, Estado e Direito, Belo Horizonte: RTM.

Massahud, R.K. (2021). Comuna e Revolução na América Central: Fetichismo e poder e a reabilitação do político, converando com K. Marx e E. Dussel sobre a constituição "de um governo do povo pelo povo". En C. B. Martins, F. R. Batista \& G. Seferian (Orgs.), Comuna de Paris, Estado e Direito, Belo Horizonte: RTM.

Molitor, T. E. (2021). Moral, trabalho e prostituição na Comuna. En C. B. Martins, F. R. Batista \& G. Seferian (Orgs.), Comuna de Paris, Estado e Direito, Belo Horizonte: RTM.

Orione, M. (2021). Às margens do Sena: por uma teoría da história da classe trabalhadora, En C. B. Martins, F. R. Batista \& G. Seferian (Orgs.), Comuna de Paris, Estado e Direito, Belo Horizonte: RTM.

Paço, E. (2021). Administração das coisas entrevista pela crítica prática ao Estado políticoburocrático. En C. B. Martins, F. R. Batista \& G. Seferian (Orgs.), Comuna de Paris, Estado e Direito, Belo Horizonte: RTM.

Passos, Lopes \& Fernandes, (2021). Sobre o problema da religião: a Comuna e para além dela. En C. B. Martins, F. R. Batista \& G. Seferian (Orgs.), Comuna de Paris, Estado e Direito, Belo Horizonte: RTM.

Prestes, R. (2021), Formas rígidas e flexíveis em movimiento de ascensão e queda: direito e Estado sob a leitura de Marx a propósito da Comuna de Prais. En C. B. Martins, F. R. Batista \& G. Seferian (Orgs.), Comuna de Paris, Estado e Direito, Belo Horizonte: RTM.Rodrigues, N. (2021). Extinção da pena de morte e a morte dos comunardos e das comunardas. En C. B. Martins, F. R. Batista \& G. Seferian (Orgs.), Comuna de Paris, Estado e Direito, Belo Horizonte: RTM.

Seferian, G. (2021). Pode a jibóia ser ecosocialista?: pontos para a retomada da experiência da Comuna de Paris como indutora da contemorânea revolução social e ecológica. En C. B. Martins, F. R. Batista \& G. Seferian (Orgs.), Comuna de Paris, Estado e Direito, Belo Horizonte: RTM. 
Souto, J. L. \& Valdete, S.S. (2021). Eleição de juízes e democratização do judiciário. En C. B. Martins, F. R. Batista \& G. Seferian (Orgs.), Comuna de Paris, Estado e Direito, Belo Horizonte: RTM.

Vasconcelos, J. (2021). "Respeitosamente diante das portas do Banque de France": a questão transicional do controle financeiro pelos trabalhadores e trabalhadoras. En C. B. Martins, F. R. Batista \& G. Seferian (Orgs.), Comuna de Paris, Estado e Direito, Belo Horizonte: RTM.

Granada (España) - Ciudad de México (México). Mayo de 2021

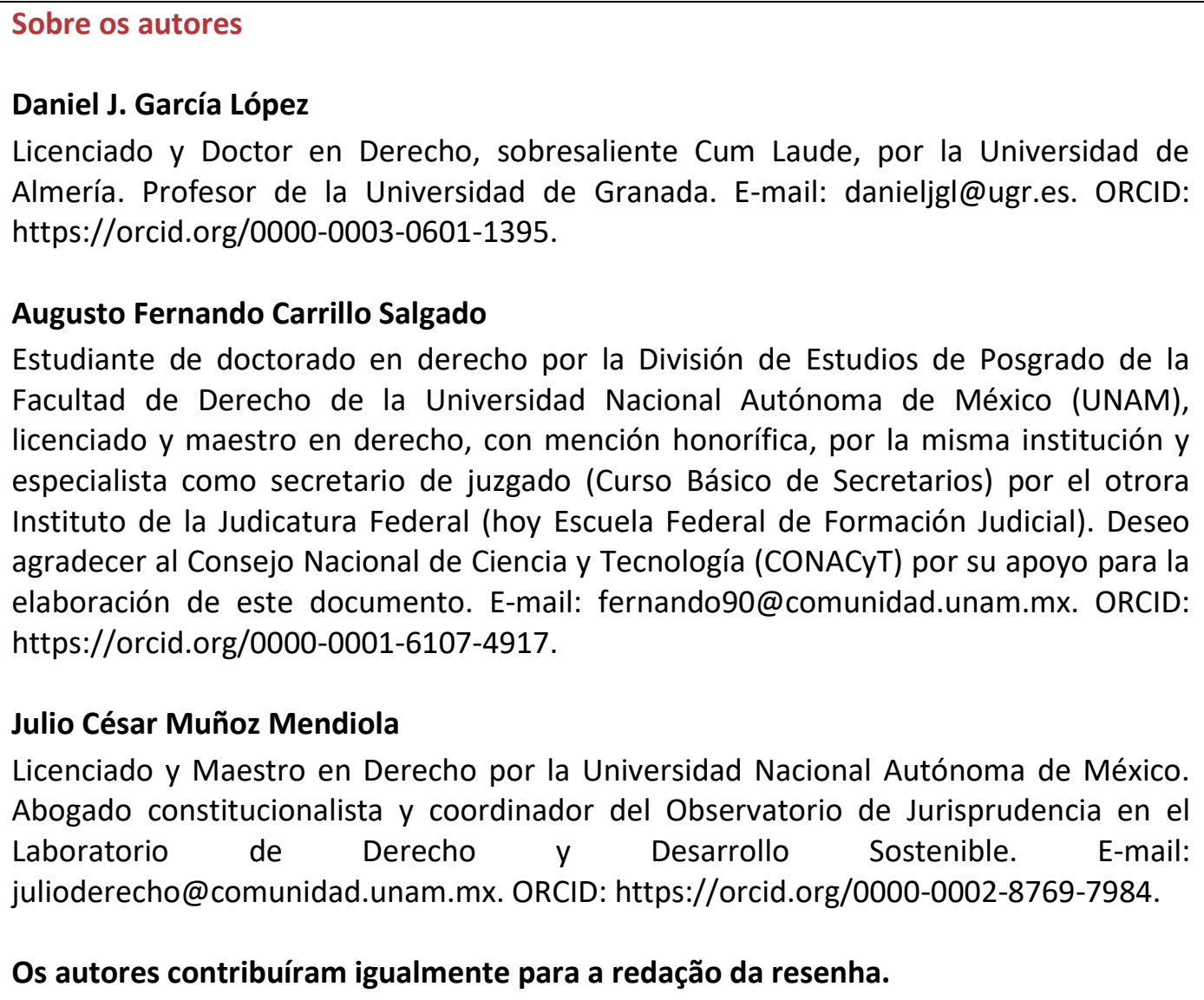

\section{Augusto Fernando Carrillo Salgado}

Estudiante de doctorado en derecho por la División de Estudios de Posgrado de la Facultad de Derecho de la Universidad Nacional Autónoma de México (UNAM), licenciado y maestro en derecho, con mención honorífica, por la misma institución y especialista como secretario de juzgado (Curso Básico de Secretarios) por el otrora Instituto de la Judicatura Federal (hoy Escuela Federal de Formación Judicial). Deseo agradecer al Consejo Nacional de Ciencia y Tecnología (CONACyT) por su apoyo para la elaboración de este documento. E-mail: fernando90@comunidad.unam.mx. ORCID: https://orcid.org/0000-0001-6107-4917.

\section{Julio César Muñoz Mendiola}

Licenciado y Maestro en Derecho por la Universidad Nacional Autónoma de México. Abogado constitucionalista y coordinador del Observatorio de Jurisprudencia en el Laboratorio de Derecho y Desarrollo Sostenible. E-mail: julioderecho@comunidad.unam.mx. ORCID: https://orcid.org/0000-0002-8769-7984.

Os autores contribuíram igualmente para a redação da resenha. 